\title{
Endocrine carcinoma of the stomach: clinicopathological analysis of 27 surgically treated cases in a single institute
}

\author{
Takeshi Kubota · Shigekazu Ohyama • \\ Naoki Hiki • Souya Nunobe • Noriko Yamamoto • \\ Toshiharu Yamaguchi
}

Received: 3 June 2011/ Accepted: 26 November 2011/Published online: 18 January 2012

(c) The International Gastric Cancer Association and The Japanese Gastric Cancer Association 2012

\begin{abstract}
Background Gastric endocrine carcinoma (EC) is an uncommon tumor of the stomach and the clinical features are not well known. Additionally, the classification and staging systems of this tumor are not yet unified worldwide. In this study, we reviewed 27 patients with gastric EC to evaluate the clinicopathological characteristics of this tumor.

Methods We retrospectively reviewed 27 patients with gastric EC among 6466 patients who had undergone gastrectomy between 1986 and 2008 at our institute. Clinicopathological features including immunohistochemistry of $\mathrm{Ki}-67$ were investigated to evaluate the malignant potential of the tumor. Furthermore, survivals were compared between the 7th edition of the International Union Against Cancer (UICC)-TNM (7th TNM) classification for gastric cancer (GC) and the new TNM classification for foregut neuroendocrine tumors (NET).

Results The median survival of the patients was 19.0 months. The 5-year survival rate was $100 \%$ in pathological stage (pStage) I, $40 \%$ in pStage II, 38\% in pStage III, and $11 \%$ in pStage IV according to the 7th TNM classification for GC. Survivals by stage showed great difference between the 7th TNM classification for GC and the new TNM classification for foregut NET, but each
\end{abstract}

T. Kubota $\cdot$ S. Ohyama $(\bowtie) \cdot$ N. Hiki $\cdot$ S. Nunobe

T. Yamaguchi

Department of Gastroenterological Surgery, Cancer Institute

Hospital, Japanese Foundation for Cancer Research,

3-8-31 Ariake, Koto-ku, Tokyo 135-8550, Japan

e-mail: oyamas@chushin-miniren.gr.jp

N. Yamamoto

Department of Pathology, Cancer Institute Hospital,

Japanese Foundation for Cancer Research, Tokyo, Japan system correlated with survival. The Ki-67 labeling index was more than $20 \%$ in most of the patients. Univariate analysis revealed that maximum tumor diameter, tumor depth, lymph node metastasis, lymphatic invasion, pStage, and curability had significant correlations with survival.

Conclusion Early detection and curative operations are essential for improving the prognosis of gastric EC. However, some adjuvant chemotherapies are required for advanced-stage tumors. Classification and staging systems may need to be unified worldwide for further analysis.

Keywords Gastric cancer - Endocrine carcinoma . Gastrectomy $\cdot$ TNM $\cdot$ Ki-67

\section{Introduction}

Gastric endocrine carcinoma (EC) is an uncommon tumor of the stomach and it has been reported that $0.1-0.6 \%$ of gastric cancers exhibit endocrine cell differentiation [1]. In general, the prognosis of patients with this tumor is extremely poor because gastric EC has aggressive biological behavior and frequently metastasizes to lymph nodes and the liver even in the early stages of the disease [2]. Rindi et al. [3] reported that angioinvasion, tumor size, clinicopathological type, mitotic index, and the Ki-67 labeling index were predictors of tumor malignancy and patient outcome. However, therapeutic guidelines and optimal surgical procedures for the treatment of gastric EC have not been established.

Gastric EC frequently contains an adenocarcinoma component. It has been proposed that gastric EC predominantly arises from endocrine precursor cell clones occurring in preceding adenocarcinoma components, which transform into EC during rapid clonal expansion [4]. This 
hypothesis was supported by correlations between the pattern of p53 protein overexpression and the concordance of common p53 mutational patterns between the gastric EC and adenocarcinoma components. Expression of p53 was associated with a high degree of cell proliferation (Ki-67positive nuclear cells) and this marker was able to predict a shorter survival time [5].

The World Health Organization (WHO) has developed a revised clinicopathological classification of neuroendocrine neoplasia of the gastroenteropancreatic tract, based on clinical malignancy [6]. At present, neuroendocrine cell neoplasia can be classified into the following subclasses: neuroendocrine tumor (NET) grade 1 (carcinoid); NET grade 2; neuroendocrine carcinoma (small and large cell type); and mixed adenoneuroendocrine carcinoma (MANEC). Of these tumors, neuroendocrine carcinoma and MANEC correspond to EC (Table 1). Recently, the European Neuroendocrine Tumor Society (ENETS) published consensus guidelines proposing a standardized approach to the diagnosis of gastroenteropancreatic NET and a prognostic stratification based on TNM classification, frequency of nuclear mitosis, and the Ki-67/MIB-1 labeling index [7]. Rindi et al. [8] presented a proposal for a new TNM classification system and Pape et al. [9] demonstrated the prognostic relevance of this system for foregut NET. However, the newest (7th) edition of the International Union Against Cancer (UICC)-TNM classification (7th TNM), which was published in 2009, proposes that highgrade neuroendocrine carcinomas should be classified according to the criteria for classifying carcinomas at the particular sites [10]. Thus, the classification and staging systems of this tumor still have some complications and are not yet unified worldwide.

In this study, we first reclassified 27 cases of gastric EC surgically treated at our institute by the 7th TNM for gastric cancer (GC) and compared the survival by pStage with the new TNM classification for foregut NET that Rindi et al. [8] and Pape et al. [9] proposed. Then we evaluated the clinicopathological features, including Ki-67 and p53 expression, which characterized the malignant potential of the gastric EC in our cases.

\section{Patients and methods}

Patients and clinicopathological features

We reviewed 27 patients diagnosed with gastric EC among 6466 patients $(0.4 \%)$ who had undergone gastrectomy between 1986 and 2008 at the Cancer Institute Hospital, Tokyo, Japan. Clinicopathological characteristics including age, gender, operation data, histological diagnosis, and survival time were obtained from our hospital database and clinical records. Tumor staging was evaluated according to the 7th TNM for GC, because it proposes that high-grade neuroendocrine carcinomas should be classified according to the criteria for classifying carcinomas at a particular site. Then we compared the survival by pStage of the 7th TNM for GC with that by pStage of the new TNM classification for foregut NET [8, 9]. Resected specimens were examined using standard hematoxylin-eosin (HE) staining. Carcinoid tumors were excluded by typical histological patterns on HE-stained slides. Specimens with histological features suggesting morphologic endocrine differentiation in one to three representative blocks [11] were investigated further with immunohistochemical stainings for general endocrine markers such as chromogranin A and synaptophysin. Specimens with $>20 \%$ positive staining for chromogranin A and/or synaptophysin were defined as EC [12].

The proliferative status of tumor cells was evaluated using Ki-67 protein antibodies (MIB-1, mouse monoclonal antibody; DAKO, Glostrup, Denmark) after microwave antigen retrieval. The Ki-67 labeling index was investigated in tumor areas containing the highest number of labeled nuclei, either by counting the number of positive cells among 2000 tumor cells (percentage evaluation) or by counting the number of labeled nuclei per 10 high-power $(\times 400)$ microscopic fields $(\times 10 \mathrm{HPF})$ [3]. Those tumors

Table 1 Classification of digestive system neuroendocrine tumors

\begin{tabular}{lll}
\hline WHO 2000 & WHO 2010 & 14th JCGC \\
\hline Well-differentiated endocrine tumor & $\begin{array}{c}\text { Neuroendocrine tumor (NET), grade 1 } \\
\text { (carcinoid) }\end{array}$ & Carcinoid tumor \\
Well-differentiated endocrine carcinoma & NET grade 2 & \\
$\begin{array}{l}\text { Small cell carcinoma, poorly differentiated } \\
\text { endocrine neoplasm }\end{array}$ & $\begin{array}{l}\text { Neuroendocrine carcinoma, small and } \\
\text { large cell type }\end{array}$ & Endocrine cell carcinoma (ECC) \\
Mixed endocrine exocrine cell carcinoma & Mixed adenoneuroendocrine carcinoma & \\
Tumor-like lesion & (MANEC) & \\
\end{tabular}

WHO World Health Organization, 14th JCGC 14th edition of the Japanese classification of gastric cancer [19] 
with $>20 \%$ positivity for $\mathrm{Ki}-67$ were defined as having a high Ki-67 labeling index. The Ki-67 labeling index was not able to be determined for one of the 27 cases. Accumulation of p53 protein expression in the endocrine components of the tumor was evaluated by immunohistochemistry after microwave antigen retrieval, using a p53-specific antibody (DO-7, mouse monoclonal antibody; DAKO). We defined p53-positive cases as those with more than $50 \%$ of tumor cells with intensively positive nuclear staining. Expression of p53 was not able to be determined for two of the cases.

\section{Statistical analysis}

JMP version 9.0 for Macintosh (SAS Institute, Cary, NC, USA) was used for all statistical analyses. Spearman's rank correlations were calculated to determine the relationship between nominal data and continuous data. The Wilcoxon signed-rank test was used to determine the correlation between two kinds of continuous data. Survival rates were calculated by the Kaplan-Meier method and survival differences between groups were determined using the logrank test. All $P$ values of less than 0.05 were considered statistically significant.

\section{Results}

Clinicopathological features and surgical outcomes

The clinicopathological features and surgical outcomes of the 27 patients with gastric EC according to the 7th TNM for GC are shown in Table 2. The male: female ratio was 20: 7. The average age of the patients was 66.3 years (range: 49-83 years). Eleven tumors were located in the upper third of the stomach, 5 in the middle, 10 in the antrum, and 1 in the whole stomach. The $\mathrm{T}$ factor was $\mathrm{T} 1$ in 4 patients, $\mathrm{T} 2$ in $2, \mathrm{~T} 3$ in 7, and $\mathrm{T} 4$ in 14 . Of the 27 patients reviewed, 20 patients $(74 \%)$ had lymph node metastasis, and 4 patients $(15 \%)$ had concurrent liver metastasis. The 27 tumors were pathologically diagnosed as pathological stage (pStage) I in 6 patients, pStage II in 5, pStage III in 7 , and pStage IV in 9 according to the 7 th TNM for GC. All of the patients underwent surgical resection of the stomach with regional lymph node dissection, and 18 of the 27 patients underwent curative resection.

Segmental gastrectomy was performed in only 2 patients, who had small pStage I tumors in the upper third of the stomach. The remaining patients underwent distal gastrectomy $(n=9)$, total gastrectomy $(n=15)$, and pancreato-duodenectomy $(n=1)$. Lymph node dissection was carried out in all patients. Splenectomy was performed in 8 of 15 patients with advanced tumors in the upper third
Table 2 Clinicopathological features and surgical outcomes of gastric endocrine carcinoma according to the 7th edition of TNM classification for gastric cancer $(n=27)$

\begin{tabular}{|c|c|}
\hline Age (years) & $66.3 \pm 8.6$ \\
\hline \multicolumn{2}{|l|}{ Gender } \\
\hline Male/female & $20 / 7$ \\
\hline \multicolumn{2}{|l|}{ Location } \\
\hline U/M/L/UML & $11 / 5 / 10 / 1$ \\
\hline \multicolumn{2}{|l|}{ Tumor depth ${ }^{\mathrm{a}}$} \\
\hline $\mathrm{T} 1 / \mathrm{T} 2 / \mathrm{T} 3 / \mathrm{T} 4$ & $4 / 2 / 7 / 14$ \\
\hline Maximum tumor diameter (mm) & $72.7 \pm 44.3$ \\
\hline \multicolumn{2}{|l|}{ Lymph node metastasis $^{\mathrm{a}}$} \\
\hline N0/N1/N2/N3 & $7 / 8 / 6 / 6$ \\
\hline Liver metastasis & 4 \\
\hline Peritoneal dissemination & 2 \\
\hline Lymphatic invasion & 22 \\
\hline Vascular invasion & 22 \\
\hline \multicolumn{2}{|l|}{ Pathological stage $^{\mathrm{a}}$} \\
\hline I/II/III/IV & $6 / 5 / 7 / 9$ \\
\hline \multicolumn{2}{|l|}{ Operation } \\
\hline Segmental gastrectomy & 2 \\
\hline Distal gastrectomy & 9 \\
\hline Total gastrectomy & 15 \\
\hline Pancreato-duodenectomy & 1 \\
\hline \multicolumn{2}{|l|}{ Curability } \\
\hline $\mathrm{R} 0 / 1 / 2$ & $18 / 0 / 9$ \\
\hline Neoadjuvant chemotherapy & 3 \\
\hline Adjuvant chemotherapy & 6 \\
\hline
\end{tabular}

$U$ upper third of the stomach, $M$ middle third of the stomach, $L$ lower third of the stomach

a The 7th edition of the International Union Against Cancer (UICC)TNM classification for gastric cancer

of the stomach. Resection was aggressively extended to adjacent organs when tumor invasion was suspected, including the liver $(n=5)$, transverse colon $(n=3)$, pancreas $(n=3)$, and diaphragm $(n=1)$.

Three patients with huge lesions and obvious lymph node metastases received neoadjuvant chemotherapy with S-1 (tegafur/gimeracil/oteracil potassium) plus cisplatin (CDDP). Six patients received adjuvant chemotherapy (3 patients received S-1 only, 2 received CDDP plus S-1 followed by CDDP plus irinotecan [CPT-11], and 1 received epirubicin plus adriamycin plus mitomycin).

\section{Comparison of survival by pStage between the 7th TNM} for GC and the new TNM classification for foregut NET

The median follow-up duration was 19.0 months (range: 0.4-149.8 months) and the 5-year survival of the patients was $43.8 \%$. Figure 1 shows the survival of patients with 


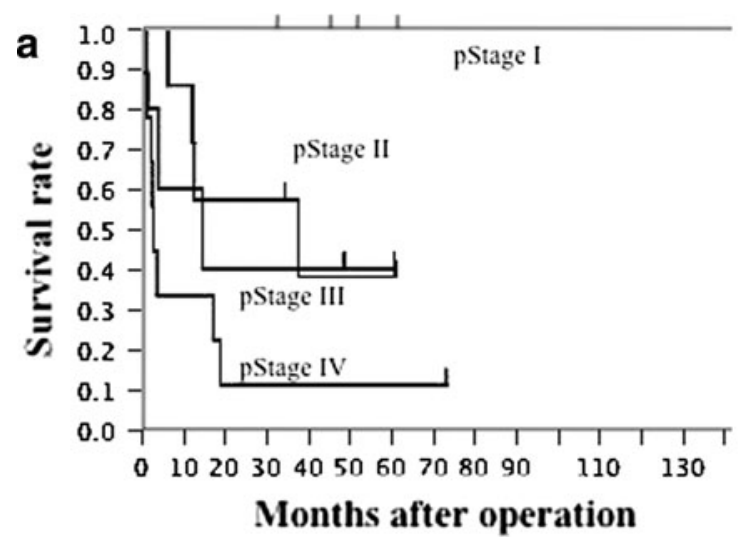

Fig. 1 Survival of 27 patients with gastric endocrine carcinoma at our institute according to the 7th edition of the International Union Against Cancer (UICC)-TNM classification for gastric cancer (a) and the new TNM classification for foregut neuroendocrine tumors (b). The new TNM classification for foregut neuroendocrine carcinoma has the following definitions: pStage I, T1N0M0; pStage II, T2 or T3N0M0; pStage III, T4N0M0 or anyTN1M0; pStage IV,

gastric EC according to the 7th TNM for GC (Fig. 1a) and the new TNM classification for foregut NET (Fig. 1b). There were great differences in survival rates by pStage between the two classification systems (Table 3). The 5 -year survival rate of pStage I in the 7th TNM for GC and that of pStage II in the new TNM classification for foregut NET were both $100 \%$. There was no difference in the 5-year survival rates between pStages II and III in the 7th TNM for GC, and the 5-year survival rates of pStages II and III in the 7th TNM for GC were similar to that of pStage III in the new TNM classification for foregut NET. However, each classification statistically reflected the prognosis of patients with gastric EC (7th TNM for GC, $P=0.0059$; new TNM classification for foregut NET, $P=0.0039$ ).

Correlation between survival and clinicopathological factors

In addition to pStage, univariate analysis revealed that maximum tumor diameter ( $<4$ vs. $\geq 4 \mathrm{~cm}$ to $<8$ vs. $\geq 8 \mathrm{~cm}$; $P<0.0001)$, tumor depth (T1/2 vs. T3/4; $P=0.0079$ ), lymph node metastasis (N0/1 vs. N2/3; $P=0.015$ ), lymphatic invasion (yes vs. no; $P=0.0201$ ), and curability (R0 vs. R1/2; $P=0.0002$ ) were significantly correlated with survival (tumor depth, lymph node metastasis, and curability were classified according to the 7th TNM for GC). The Ki-67 labeling index was not significantly different between the tumors with high and low values, because it was high in most of the patients. Liver metastasis, vascular invasion, and p53 expression did not correlate with prognosis (Table 3).

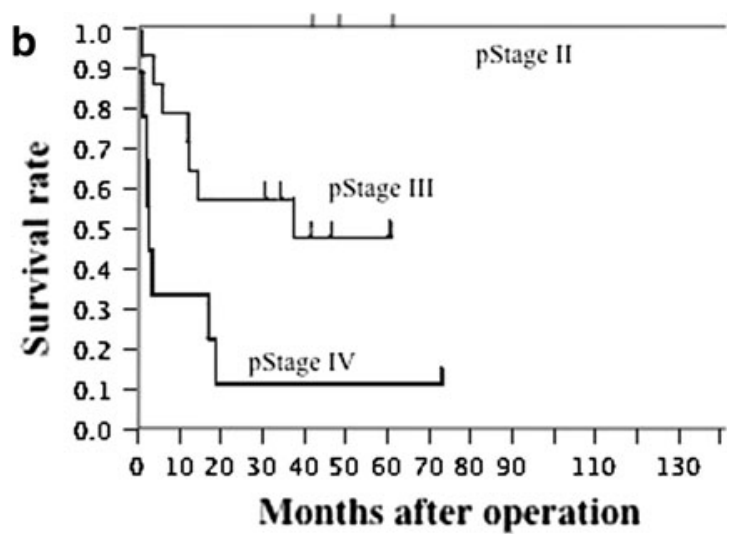

anyTanyNM1. T1, gastric tumor invading the lamina propria or submucosa and size $<10 \mathrm{~mm}$; T2, gastric tumor invading the muscularis propria or subserosa, or size $>10 \mathrm{~mm}$; T3, gastric tumor penetrating the serosa; T4, gastric tumor invading an adjacent structure. NO indicates absence of regional lymph node metastasis; $\mathrm{N} 1$, invasion of regional lymph nodes. M0 indicates absence of distant metastasis; M1, presence of distant metastasis [8, 9]

Correlation between Ki-67 labeling index and clinicopathological factors

The relationships between the clinicopathological characteristics and the Ki-67 labeling index are shown in Fig. 2. Because most of the patients with gastric EC showed strong expression of Ki-67, we did not use a $20 \%$ cut-off value but used the raw data of the Ki-67 labeling index. Although a tendency is obvious in the graphs shown in Fig. 2, tumor depth (Fig. 2a: $P=0.1328$ ), pStage (Fig. 2b: $P=0.1252$ ), and maximum tumor diameter (Fig. 2c: $\left.R^{2}=0.023, P=0.4687\right)$ did not show significant correlations with the Ki-67 labeling index (tumor depth and pStage were classified according to the 7th TNM for GC). Only p53 expression showed a statistically significant correlation with the Ki-67 labeling index (Fig. 2d: p53 positive vs. p53 negative; $P=0.006$ ).

\section{Discussion}

In our review of 27 patients with gastric EC, we found that there was a large difference in survival by pStage between the 7th TNM for GC and the new TNM classification for foregut NET, but each classification was significantly correlated with survival. In Japan, gastric EC has been classified and staged as a special type of gastric cancer. In 2000, the Japanese Classification of Gastric Carcinoma (JCGC) was largely revised referring to the 7th TNM for GC, and stated that gastric EC corresponded to poorly differentiated neuroendocrine carcinoma (small cell carcinoma and endocrine carcinoma containing an adenocarcinoma 
Table 3 Univariate analysis of clinicopathological factors related to the survival of patients with gastric endocrine carcinoma $(n=27)$

\begin{tabular}{|c|c|c|c|}
\hline Variables & $\begin{array}{l}\text { Patients } \\
(n)\end{array}$ & $\begin{array}{l}5 \text {-Year survival } \\
\text { rate }(\%)\end{array}$ & $P$ value \\
\hline Gender & & & 0.3296 \\
\hline Male & 20 & 39.4 & \\
\hline Female & 7 & 57.1 & \\
\hline $\begin{array}{l}\text { Maximum tumor diameter } \\
(\mathrm{cm})\end{array}$ & & & $<0.0001$ \\
\hline$<4$ & 7 & 85.7 & \\
\hline$\geq 4$ to $<8$ & 10 & 48.0 & \\
\hline$\geq 8$ & 10 & 10.0 & \\
\hline Tumor depth ${ }^{\mathrm{a}}$ & & & 0.0079 \\
\hline $\mathrm{T} 1 / 2$ & 6 & 100.0 & \\
\hline $\mathrm{T} 3 / 4$ & 21 & 27.8 & \\
\hline Lymph node metastasis ${ }^{a}$ & & & 0.0015 \\
\hline $\mathrm{N} 0 / 1$ & 15 & 76.9 & \\
\hline $\mathrm{N} 2 / 3$ & 12 & 10.7 & \\
\hline Liver metastasis & & & 0.3879 \\
\hline Yes & 4 & 25.0 & \\
\hline No & 23 & 47.0 & \\
\hline Lymphatic invasion & & & 0.0201 \\
\hline Yes & 22 & 31.2 & \\
\hline No & 5 & 100.0 & \\
\hline Vascular invasion & & & 0.1244 \\
\hline Yes & 22 & 35.8 & \\
\hline No & 5 & 80.0 & \\
\hline Pathological stage $^{\mathrm{a}}$ & & & 0.0059 \\
\hline pStage I & 6 & 100.0 & \\
\hline pStage II & 5 & 40.0 & \\
\hline pStage III & 11 & 38.1 & \\
\hline pStage IV & 5 & 11.1 & \\
\hline Pathological stage $^{\mathrm{b}}$ & & & 0.0039 \\
\hline pStage I & 0 & - & \\
\hline pStage II & 4 & 100.0 & \\
\hline pStage III & 18 & 47.6 & \\
\hline pStage IV & 5 & 11.1 & \\
\hline Curability $^{\mathrm{a}}$ & & & 0.0002 \\
\hline R0 & 18 & 65.7 & \\
\hline $\mathrm{R} 1 / 2$ & 9 & 0 & \\
\hline Ki-67 index & & & 0.3549 \\
\hline High $(>20 \%)$ & 25 & 43.7 & \\
\hline Low $(\leq 20 \%)$ & 1 & 100.0 & \\
\hline p53 & & & 0.3099 \\
\hline Positive & 14 & 35.7 & \\
\hline Negative & 11 & 53.0 & \\
\hline
\end{tabular}

a The 7th edition of the UICC-TNM classification for gastric cancer

b The new TNM classification for foregut neuroendocrine tumors

component). The newest JCGC (14th edition) quotes the TNM staging system from the 7th TNM for carcinoid tumors, but this staging system is not for gastric EC, but for carcinoid tumors [13]. The 7th TNM classification also proposes that high-grade neuroendocrine carcinomas should be classified according to the criteria for classifying carcinomas [10]. Thus, the classification and staging systems of NETs are still developing. Therefore, in the present study, we reclassified our cases of gastric EC by the 7th TNM for GC and compared the survival by pStage with the new TNM classification for foregut NET.

The poor prognosis of gastric EC seems to be due to potent microvessel invasiveness and subsequent frequent metastasis to lymph nodes and the liver even in the early stages of the disease [2,14]. Chiba et al. [15] revealed in their retrospective review of 119 cases that gastric EC was shown to have significantly more frequent incidences of lymphatic invasion (ly: 88.9 vs. $56.6 \%$ ), vascular invasion (v: 75.6 vs. $31.6 \%$ ), and lymph node metastases (n: 82.1 vs. $58.8 \%$ ) compared to those in ordinary gastric cancer (GC). In the present 27 cases, lymphatic invasion was found in 22 cases $(81.5 \%)$, vascular invasion in 22 cases $(81.5 \%)$, and lymph node metastasis in 20 cases $(74.1 \%)$. Our univariate analysis also suggested the importance of lymphatic invasion, vascular invasion (not statistically significant, but a great difference between the presence and absence of vascular invasion), and lymph node metastasis for survival.

In a review of the literature, the 5-year survival rate of gastric EC was reported to be 30-40\% [3, 9, 13, 16-19]. Our 5 -year survival of $43.8 \%$ was similar to the results of some of these previous reports (Table 4). Despite the better prognosis of pStage I in the 7th TNM for GC and pStage II in the new TNM classification for foregut NET, the 5-year survival rates of more advanced cases were invariably poor. Jiang et al. [12] performed survival analysis only by stage and showed the markedly poor prognosis of especially advanced EC. On the other hand, we found a great difference in survival rates between the 7th TNM for GC and the new TNM classification for foregut NET. Most of the cases of pStages I and II in the 7th TNM for GC were upstaged to pStages II and III in the new TNM classification for foregut NET because of the tumor size and the presence of lymph node metastasis. In the 7th TNM for GC, the T category is defined as T1: tumor invading the mucosa (M) or submucosa (SM), T2: tumor invading the muscularis propria (MP), T3: tumor invading the subserosa (SS), and T4: tumor penetrating the serosa (SE) or invading adjacent structures (SI), while in the 7th TNM classification for foregut NET, the $\mathrm{T}$ category is defined as $\mathrm{T} 1 \mathrm{M}$ or $\mathrm{SM}$ and size $<10 \mathrm{~mm}$, T2: MP or SS, or size $>10 \mathrm{~mm}, \mathrm{~T} 3$ : SE, and T4: SI. On the other hand, in the 7th TNM for GC, the N category depends on the number of lymph node metastases (N0: no lymph node metastasis, N1: 1-2 regional lymph node metastases, N2: 3-6 regional lymph node metastases, and N3: 7 or more regional lymph node metastases), while in the 7th TNM classification for foregut NET the $\mathrm{N}$ category depends on 

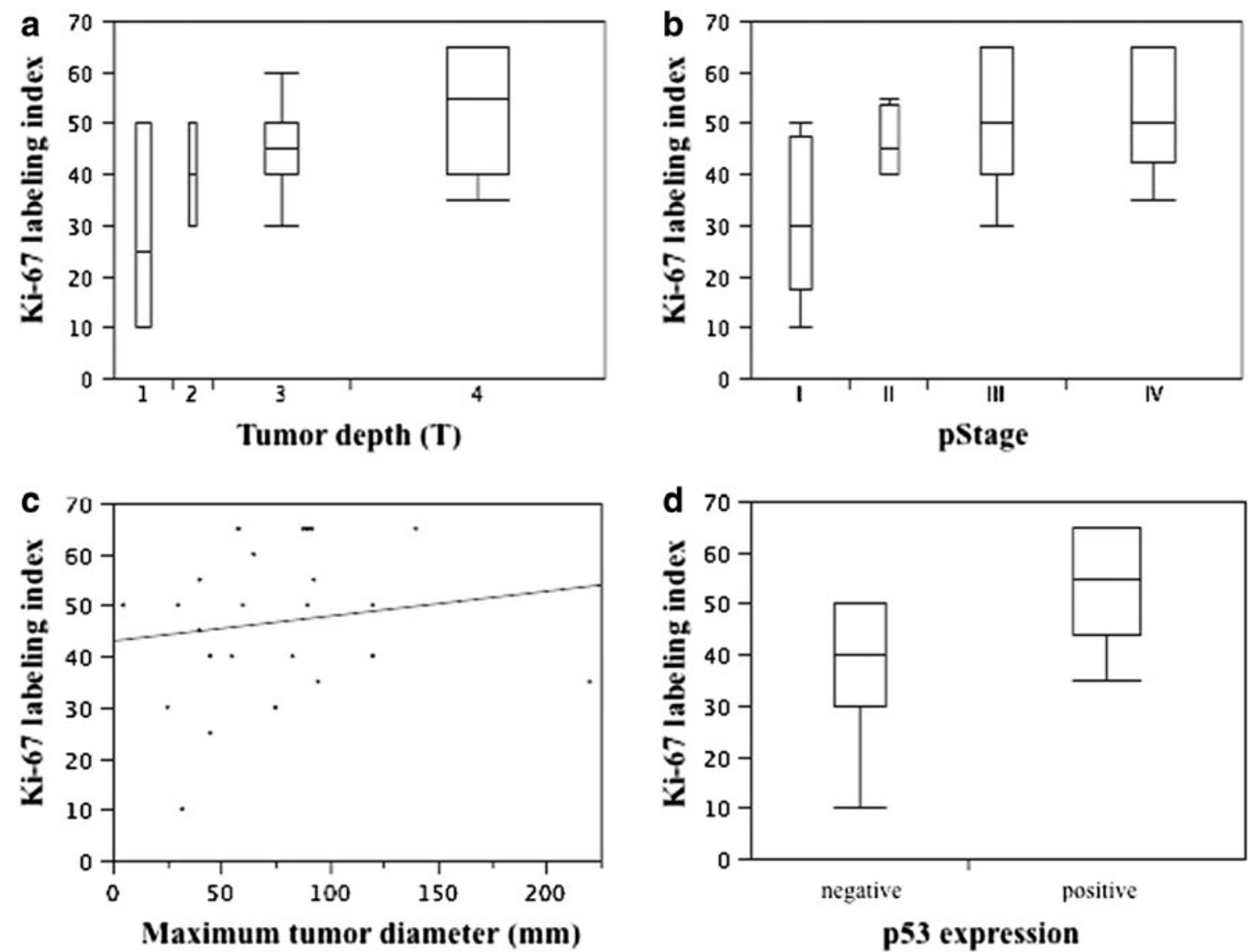

Fig. 2 Correlation of Ki-67 labeling index with a tumor depth, b pathological stage, $\mathbf{c}$ maximum tumor diameter, and d p53 expression. Tumor depth and pathological stage are given according to the 7th TNM for gastric cancer

Table 4 Survival of patients with gastric endocrine carcinoma in previous studies

\begin{tabular}{|c|c|c|c|c|c|}
\hline Authors & Year & Pathological type & $\begin{array}{l}\text { No. of } \\
\text { patients }\end{array}$ & $\begin{array}{l}5 \text {-Year survival } \\
\text { rate }(\%)\end{array}$ & Survival time, other data \\
\hline Matsui et al. [16] & 1998 & $\begin{array}{l}\text { Neuroendocrine carcinoma (small and } \\
\text { large cell carcinoma) }\end{array}$ & 33 & - & $\begin{array}{l}\text { Mean survival time, } 14.9 \text { months; 1-year } \\
\text { survival rate, 53\% }\end{array}$ \\
\hline Rindi et al. [3] & 1999 & Poorly differentiated endocrine carcinoma & 22 & $<10^{\mathrm{a}}$ & Median survival, 8 months \\
\hline \multirow[t]{2}{*}{ Jiang et al. [12] } & 2006 & Large cell neuroendocrine carcinoma & 42 & 31.1 & Stage I/II, $50 \%$; stage III/IV, $0 \%^{\mathrm{a}, \mathrm{b}}$ \\
\hline & & $\begin{array}{l}\text { Adenocarcinoma with neuroendocrine } \\
\text { differentiation }\end{array}$ & 44 & 34.7 & $\begin{array}{l}\text { Stage I, } 75-80 \% \text {; stage II/III, 25-30\%; } \\
\text { stage IV, } 0 \%{ }^{\text {a,b }}\end{array}$ \\
\hline Boo et al. [17] & 2007 & Poorly differentiated endocrine carcinoma & 12 & $<20^{\mathrm{a}}$ & Median survival time, 15 months \\
\hline Pape et al. [9] & 2008 & Poorly differentiated endocrine carcinoma & 26 & 36.6 & \\
\hline Kim et al. [18] & 2010 & Poorly differentiated endocrine carcinoma & 52 & 41.6 & \\
\hline Okita et al. [19] & 2011 & Poorly differentiated endocrine carcinoma & 22 & 33 & Median survival time, 33 months \\
\hline
\end{tabular}

${ }^{a}$ Obtained from the survival curve in Figure 5 of this reference

b The 5th edition of the UICC-TNM classification for gastric cancer

the presence of lymph node metastasis (N0: absence of lymph node metastasis, N1: presence of lymph node metastasis). The differences in survival between the two classification systems are likely to be due to the fundamental differences in the $\mathrm{T}$ and $\mathrm{N}$ categories. Tumor size was also an important prognostic marker, and the new TNM classificationfor foregut NET reflects not only tumor depth but also tumor size in the T category.

With regard to lymph node metastasis, our univariate analysis showed a significant difference in survival 
between N0/1 and N2/3 according to the 7th TNM for GC. The same result was obtained in comparison between N0/1 and N2/3 according to the former JCGC (13th edition), in which the $\mathrm{N}$ category was classified into three groups depending on the anatomical position of the lymph node station (data not shown) [20]. In fact, we have treated gastric EC according to the former JCGC and Japanese Gastric Cancer Treatment Guidelines, and most patients underwent gastrectomy with standard lymph node dissection. Thus, our results of univariate analysis indicate the importance of earlier detection and a curative operation with standard regional lymph node dissection for extending the survival of patients with gastric EC.

The ENETS states aggressive surgery and chemotherapy should be considered for any neuroendocrine carcinomas, grade 3 either small cell or large cell with more organoid, poorly differentiated history [7]. The National Comprehensive Cancer Network (NCCN) guideline also recommends that NET, including carcinomas, should be considered for definitive resection. This can be accompanied by the concomitant resection of adjacent organs when required, to completely remove the directly invaded adjacent structure [21]. However, many authors recognize that an operation alone may not be sufficient treatment and emphasize the importance of adjuvant chemotherapy, especially for advanced cases [7, 22]. Fukuda et al. [23] concluded that intensive chemotherapy with or without an operation should be recommended for tumors at any stage. In our study, all of the 11 patients with pStage I and II (7th TNM for GC) were treated with an operation alone. The 5-year survival rate of patients with pStage I was 100\%; however, the prognosis of patients with pStage II was extremely poor and was similar to that of patients with pStage III although we had performed complete resection of the tumor with lymph node dissection. Adjuvant chemotherapy was performed in only 5 patients with pStage III and 1 with pStage IV. However, we found no survival benefit of adjuvant chemotherapy for advanced gastric EC. Recently, some authors have reported successfully treating cases of gastric EC with different combination chemotherapies, such as etoposide/CDDP, CPT-11/CDDP, and S-1/CDDP [19, 22, 24-28]. However, at present there is no standard chemotherapy regimen for advanced gastric EC.

Expression of Ki-67 and p53 likely reflects the malignant potential of EC and is used to differentiate EC from carcinoids. A high Ki-67 proliferation index could be used as a prognostic marker to predict aggressive gastric EC [17] and the ENETS grading system accepts a Ki-67 labeling index of more than $20 \%$ as grade 3 [7]. On the other hand, it is well known that p53 mutations are the most common genetic alterations in ordinary GC [29-31]. Nishikura et al. [4] showed that p53 overexpression was observed in 58.8\% of gastric ECs, but not in gastric carcinoid tumors. Expression of p53 was associated with a high degree of cell proliferation (Ki-67-positive nuclear cells) and this marker also was able to predict a shorter survival time [5]. Thus, tumor progression is likely to accelerate cell proliferation, as reflected by the Ki-67 labeling index. Our data revealed that most of our patients showed strong Ki-67 expression (Ki-67 labeling index of more than 20\% ) and 56\% of the patients expressed p53 in their EC components. The p53 expression did not correlate with survival, but when we assessed the correlation between the Ki-67 labeling index and clinicopathological factors in the criteria of gastric EC, the Ki-67 labeling index had a tendency to correlate with tumor depth, tumor size, pStage, and p53 expression. In this context, it can be said that the Ki-67 labeling index is an important predictor of malignant potential.

In conclusion, early detection and curative operations are essential for improving the prognosis of gastric EC. However, some adjuvant chemotherapies are required for stages more advanced than pStage II (7th TNM for GC) or pStage III (new TNM classification for foregut NET). Tumor diameter, tumor depth, lymph node metastasis, lymphatic invasion, Ki-67 labeling index, pStage, and curability were also confirmed to be important predictors of the malignant potential of gastric EC in our patients. Because gastric EC is an uncommon tumor, classification and staging systems may need to be unified worldwide for further analysis.

\section{References}

1. Matsubayashi H, Takagaki S, Otsubo T, Iiri T, Kobayashi Y, Yokota $\mathrm{T}$, et al. Advanced gastric glandular-endocrine cell carcinoma with 1-year survival after gastrectomy. Gastric Cancer. 2000;3:226-33.

2. Matsui K, Kitagawa M, Miwa A, Kuroda Y, Tsuji M. Small cell carcinoma of the stomach: a clinicopathologic study of 17 cases. Am J Gastroenterol. 1991;86:1167-75.

3. Rindi G, Azzoni C, La Rosa S, Klersy C, Paolotti D, Rappel S, et al. ECL cell tumor and poorly differentiated endocrine carcinoma of the stomach: prognostic evaluation by pathological analysis. Gastroenterology. 1999;116:532-42.

4. Nishikura K, Watanabe H, Iwafuchi M, Fujiwara T, Kojima K, Ajioka Y. Carcinogenesis of gastric endocrine cell carcinoma: analysis of histopathology and p53 gene alteration. Gastric Cancer. 2003;6:203-9.

5. Safatle-Ribeiro AV, Ribeiro U Jr, Corbett CE, Iriya K, Kobata $\mathrm{CH}$, Sakai P, et al. Prognostic value of immunohistochemistry in gastric neuroendocrine (carcinoid) tumors. Eur J Gastroenterol Hepatol. 2007;19:21-8.

6. Bosman FT, Carneiro F, Theise ND. Nomenclature and classification of neuroendocrine neoplasms of digestive system. WHO classification of tumours of the digestive system. 4th ed. Lyon: IARC; 2010. p. 13-14.

7. Klöppel G, Couvelard A, Perren A, Komminoth P, McNicol AM, Nilsson $\mathrm{O}$, et al. Mallorca Consensus Conference participants; 
European Neuroendocrine Tumor Society. ENETS consensus guidelines for the standards of care in neuroendocrine tumors: towards a standardized approach to the diagnosis of gastroenteropancreatic neuroendocrine tumors and their prognostic stratification. Neuroendocrinology. 2009;90:162-6.

8. Rindi G, Kloppel G, Ahlmann H, Caplin M, Couvelard A, de Herder WW, et al. and all other Frascati Consensus Conference participants; European Neuroendocrine Tumor Society (ENETS). TNM staging of foregut (neuro)endocrine tumors: a consensus proposal including a grading system. Virchow Arch. 2006;449: 395-401.

9. Pape UF, Jann H, Muller-Nordhorn J, Bockelbrink A, Berndt U, Koch M, et al. Prognostic relevance of a novel TNM classification system for upper gastroenteropancreatic neuroendocrine tumors. Cancer. 2008;113:256-65.

10. Sobin LH, Gospodarowicz MK, Wittekind C. TNM classification of malignant tumours. 7th ed. New York: Wiley-Blackwell; 2009.

11. Shia J, Tang LH, Weiser MR, Brenner B, Adsay NV, Stelow EB, et al. Is nonsmall cell type high-grade neuroendocrine carcinoma of the tubular gastrointestinal tract a distinct disease entity? Am J Surg Pathol. 2008;32:719-31.

12. Jiang SX, Mikami T, Umezawa A, Saegusa M, Kameya T, Okayasu I. Gastric large cell neuroendocrine carcinomas: a distinct clinicopathologic entity. Am J Surg Pathol. 2006;30:945-53.

13. Japanese Gastric Cancer Association. Japanese classification of gastric carcinoma. 14th ed (in Japanese). Tokyo: Kanehara \& Co., Ltd.; 2010.

14. Fukuda T, Ohnishi Y, Nishimaki T, Ohtani H, Tachikawa S. Early gastric cancer of the small cell type. Am J Gastroenterol. 1988;83:1176-9.

15. Chiba N, Suwa T, Hori M, Sakuma M, Kitajima M. Advanced gastric endocrine cell carcinoma with distant lymph node metastasis: a case report and clinicopathological characteristics of the disease. Gastric Cancer. 2004;7:122-7.

16. Matsui K, Jin MX, Kitagawa M, Miwa A. Clinicopathologic features of neuroendocrine carcinomas of the stomach. Arch Pathol Lab Med. 1998;122:1010-7.

17. Boo YJ, Park SS, Kim JH, Mok YJ, Kim SJ, Kim CS. Gastric neuroendocrine carcinoma: clinicopathologic review and immunohistochemical study of E-cadherin and $\mathrm{Ki}-67$ as prognostic markers. J Surg Oncol. 2007;95:110-7.

18. Kim BS, Oh ST, Yook JH, Kim KC, Kim MG, Jeong JW, et al. Typical carcinoid and neuroendocrine carcinomas of the stomach: differing clinical courses and progress. Am J Surg. 2010;200:328-33.

19. Okita Tsuda N, Kato K, Takahari D, Hirashima Y, Nakajima TE, Matsubara $\mathrm{J}$, et al. Neuroendocrine tumors of the stomach: chemotherapy with cisplatin plus irinotecan is effective for gastric poorly-differentiated neuroendocrine carcinoma. Gastric Cancer. 2011;14:161-5.

20. Japanese Gastric Cancer Association. Japanese classification of gastric carcinoma. 13th ed (in Japanese). Tokyo: Kanehara \& Co., Ltd.; 1998.

21. National Comprehensive Cancer Network (NCCN). Clinical practice guidelines in oncology. Neuroendocrine tumors. v.2. 2010. http://www.ncen.org

22. Namikawa T, Kobayashi M, Okabayashi T, Ozaki S, Nakamura $\mathrm{S}$, Yamashita K, et al. Primary gastric small cell carcinoma: report of a case and review of the literature. Med Mol Morphol. 2005;38:256-61.

23. Fukuda T, Ohnishi Y, Nishimaki T, Ohtani H, Tachikawa S. Early gastric cancer of the small cell type. Am J Gastroenterol. 1988;83:1176-9.

24. Moertel CG, Kvols LK, O'Connell MJ, Rubin J. Treatment of neuroendocrine carcinomas with combined etoposide and cisplatin. Evidence of major therapeutic activity in the anaplastic variants of these neoplasms. Cancer. 1991;68:227-32.

25. Koide N, Suzuki A, Saito H, Sato T, Murakami M, Ota H, et al. Gastric small cell carcinoma successfully treated by surgery and postoperative chemotherapy consisting of cisplatin and S-1: report of a case. Surg Today. 2007;37:989-94.

26. Kirii Y, Ichikawa C, Miyamoto M, Hata M, Miyairi J, Takagi H, et al. A case of gastric large cell neuroendocrine carcinoma (LCNEC) for whom chemotherapy of CDDP + CPT-11 proved very effective. Gan To Kagaku Ryoho. 2010;37:895-8. In Japanese.

27. Ohhinata R, Iwasaki Y, Ohashi M, Iwanaga T, Takahashi K, Yamaguchi T, et al. A case of gastric endocrine cell carcinoma with liver metastases treated with S-1/CDDP. Gan To Kagaku Ryoho. 2010;37:2508-10. (In Japanese).

28. Tsushima T, Tsuji Y, Abe S, Tamura F, Mizushima T, Nagashima $\mathrm{H}$, et al. A case of metastatic gastric endocrine cell carcinoma which could be curably resected after chemotherapy with S-1/CDDP. Gan To Kagaku Ryoho. 2008;35:817-20. (In Japanese).

29. Tahara E. Molecular mechanism of stomach carcinogenesis. J Cancer Res Clin Oncol. 1993;119:265-72.

30. Uchino S, Noguchi M, Ochiai A, Saito T, Kobayashi M, Hirohashi S. p53 mutation in gastric cancer: a genetic model for carcinogenesis is common to gastric and colorectal cancer. Int $\mathrm{J}$ Cancer. 1993;54:759-64.

31. Renault B, van den Broek M, Fodde R, Wijnen J, Pellegata NS, Amadori D, et al. Base transitions are the most frequent genetic changes at P53 in gastric cancer. Cancer Res. 1993;53:2614-7. 